\title{
LA METÁFORA Y LA COSMOVISIÓN ANDINA EN UN POEMA DE JOSÉ MARÍA ARGUEDAS: "TUPAC AMARU KAMAQTAYTANCHISMAN (HAYLLI-TAKI)"
}

\author{
Nehemías Vega Mendieta
}

\begin{abstract}
RESUMEN
El presente trabajo es un estudio sobre la relación entre la metáfora y la cosmovisión andina que se configura en el poema "Tupac Amaru kamaqtaytanchisman (hayllitaki) [A nuestro padre creador Tupac Amaru (himno-canción)]", el cual fue escrito originalmente en quechua y traducido al castellano por el propio José María Arguedas, con lo cual cumple el doble papel de autor y traductor. A lo largo del poema podemos hallar metáforas que reflejan elementos culturales de la cultura andina y que crean un mundo representado que une el mito y la historia. Nuestro análisis se centrará en el estudio de la metáfora y cómo esta opera en el poema para reflejar la cosmovisión andina.
\end{abstract}

Palabras claves: Metáfora, poesía quechua, etnopoética, José María Arguedas, Katatay, cosmovisión andina, figura literaria

\begin{abstract}
The present text is a study about the relation between the metaphor and the Andean view of the world that is formed in the poem "Tupac Amaru kamaqtaytanchisman (haylli-taki) [A nuestro padre creador Tupac Amaru (himno-canción)] ", who was written originally in Quechuan and translated to the Spanish for the own Jose Maria Arguedas, with which he performs the double paper of author and translator. Across the poem, we can find metaphors that reflect cultural elements of the Andean culture that create a represented world that joins the myth and the history. Our analysis will centre on the study of the metaphor and how this one operates in the poem to reflect the Andean view of the world.
\end{abstract}

Keywords: Metaphor, Quechua poetry, Jose Maria Arguedas, Katatay, Andean view of the world, literary figure 


\section{INTRODUCCIÓN}

La metáfora es la figura más estudiada dentro del campo de la retórica y sobre ella hay varias perspectivas teóricas. Algunos estudiosos la asumían como un mero desvío de la norma lingüística y que solo pertenecía al campo de la literatura, pero los últimos estudios realizados por la neorretórica han planteado que esta no solo opera dentro del discurso literario, sino que se utiliza en todo tipo de discurso, no solo aquel que tiene un fin estético. La metáfora es un vehículo de conocimiento y por lo tanto una manera de ver el mundo. El presente texto tratará sobre la metáfora y la cosmovisión andina que subyace en el poema "Tupac Amaru kamaqtaytanchisman (haylli-taki) [A nuestro padre creador Tupac Amaru (himnocanción)]". Para estudiar el concepto de metáfora lo haremos desde dos perspectivas; por un lado, utilizaremos la teoría propuesta por Stefano Arduini, George Lakoff y Mark Johnson y la segunda perspectiva la tomaremos del estudio realizado por William Hurtado de Mendoza en su libro titulado Metáfora y pensamiento de la cultura quechua (2009).

El poema que nos concierne pertenece al libro Katatay de José María Arguedas, aparecido el año 1972, y su análisis representa un reto para la comunidad de investigadores, pues el poema fue escrito originalmente en lengua quechua y ha sido traducido por el mismo autor a la lengua española. El escritor José María Arguedas, como sabemos, fue bilingüe, pues vivió en su niñez en una comunidad andina donde incorporó la lengua y la cultura quechua. Al traducir un texto literario hay siempre algo que se pierde, y a veces que no se entiende, pues el signo lingüístico de una comunidad a otra, tiene una connotación diferente, por ello, el trasvase del contenido de una lengua a otra no siempre se mantiene intacto. Veremos más adelante cual era el planteamiento del autor para solucionar el problema de la comprensión de la lectura e interpretación del poema.

Es imposible trasvasar el mismo contenido de una lengua a otra, ya que una lengua no es solamente un conjunto de signos lingüísticos y reglas combinatorias, sino que la lengua también implica una cosmovisión, una manera de ver el mundo, un sistema simbólico construido a partir del lenguaje. De acuerdo a los últimos estudios de la neorretórica, se ha llegado a la conclusión de que la "capacidad referencial del signo lingüístico, solo tiene valor al funcionar dentro del contexto propio de su expresión" (Hurtado de Mendoza 2009). Y sabemos que la cultura quechua presenta una cosmovisión distinta de la occidental. Decimos esto porque nuestro desconocimiento de la lengua quechua, nos obligará a centrarnos en la versión castellana realizada por el mismo José María Arguedas que como poeta bicultural ha buscado ser fiel a sí mismo.

En el primer apartado de nuestro trabajo, estudiaremos el concepto de metáfora a partir de las ideas de vertidas en Prolegómenos a una teoría general de las figuras (2000) de Stefano Arduini y Metáforas de la vida cotidiana (1980) de George Lakoff y Mark Johnson y como mencionamos utilizaremos el texto de William Hurtado de Mendoza Metáfora y pensamiento de la cultura quechua. 
En el segundo capítulo, analizaremos el poema en sí. Procederemos primero a estudiar la estructura del poema y explicaremos cada segmento. Como segundo paso, determinaremos cuál es el campo figurativo que predomina y rastrearemos las figuras literarias más importantes. Luego, realizaremos como tercer procedimiento un análisis de la comunicación que se opera a partir de los interlocutores del poema. Por último, veremos cuál es la cosmovisión que se refleja en el texto, motivo de nuestro análisis.

\section{MARCO TEÓRICO}

En este capítulo explicaremos el concepto de campo retórico a partir de lo planteado por Stefano Arduini, pero antes de centrarnos en la propuesta de este autor mencionaremos algunos alcances sobre la retórica, luego hablaremos de la propuesta de metáfora de Lakoff y Johnson y la de Hurtado de Mendoza.

\section{Campo retórico}

El italiano Stefano Arduini, en su libro Prolegómenos a una teoría general de las figuras (2000), fue quien rescata la importancia de las figuras, pues no son solo elementos posibilitadores de conocimiento, sino que son recursos que configuran la realidad, pues esta es una construcción o convención creada por el hombre que se opera a través del lenguaje, el cual es un elemento modelador de la realidad.

La relación que conecta lenguaje y realidad es una relación entre elementos de un sistema que no puede separar el objeto del mensaje respecto del sujeto hablante y del medio con el que habla. Todos estos elementos están en una relación de interdependencia, se constru- yen recíprocamente. (...) la retórica asume un valor completamente nuevo en el ámbito de las disciplinas del discurso; la retórica tiene la tarea de indagar en los puntos de intersección, en las grandes configuraciones expresivas que muestran las vías a través de las cuales la realidad viene organizándose en la observación, configuraciones universales, que atraviesan los límites de las lenguas concretas y de los sistemas sígnicos particulares, para constituir una red estructuralmente más profunda. (2000: 43)

Como vemos, la retórica de Arduini se opone a la idea general de muchos teóricos lingüistas y literarios de que hay una oposición entre norma/desvío y sentido literal/ sentido figurado, pues niega que el discurso retórico sea un discurso de segundo grado, creado a partir de un discurso anterior, ya que realmente desde que el hombre ha desarrollado el lenguaje ha utilizado figuras, por ello estas no son un desvío de la norma lingüísti$\mathrm{ca}$, sino que son la base misma del lenguaje. Arduini resalta el rol de las figuras y la importancia de la retórica, pues estas nos ayudan a la construcción y conocimiento de la realidad y que son importantes para el hombre pues como sujeto-hablante son instrumentos para construir y conocer su realidad. Lo esencial en Arduini es que él reconoce una relación directa entre lenguaje y realidad, pues usamos el lenguaje como un modelador de la realidad, por ello, las figuras no son desviaciones del lenguaje, sino que son maneras de pensar la realidad, son "categorías más generales de la expresión que orientan nuestra forma de percibir el mundo".

La propuesta de Arduini va a establecer categorías que van a ser importantes para la configuración de su sistema teórico. Entre ellas tenemos la de hecho retórico, el cual se concibe como "acontecimiento que conduce a la producción de 
un texto retórico"; el texto retórico, que se asume como el producto lingüístico. Y también plantea el concepto de campo retórico que en palabras de Arduini es:

\begin{abstract}
"(...) la vasta área de los conocimientos y de las experiencias comunicativas adquiridas por $\mathrm{el}$ individuo, por la sociedad y por las culturas. Es el depósito de las funciones y de los medios comunicativos formales de una cultura $y$, en cuanto tal, es el substrato necesario de toda comunicación. En este sentido, el Campo Retórico viene a estar constituido por la 'interacción' de los hechos retóricos sea en sentido sincrónico, sea en sentido diacrónico". (2000: 47)
\end{abstract}

Por lo tanto, el campo retórico implica el conjunto conocimientos que posee un individuo, una sociedad o una cultura. Este concepto es importante para entender la obra de Arguedas o la de cualquier otro autor pues un texto responde a una visión del mundo y, por lo tanto, se mueve dentro de un campo retórico, un determinado horizonte cultural.

\section{Campos figurativos}

Las figuras literarias o retóricas, como mencionamos, no fueron concebidas como simples adornos lingüísticos, ni tampoco como desviaciones de la norma, pues el lenguaje desde su origen ha sido figurado y la distinción entre denotación y connotación es relativa, ni siquiera el discurso científico que era tomado como ejemplo del grado cero de la escritura deja de usar metáforas y muchos de sus modelos teóricos están construidos a partir de figuras retóricas. Tal como señala Arduini: “(..) las figuras representan algo más profundo: unas estructuras universales de organización expresiva del pensamiento no reductibles a la simple dialéctica normadesvio" (2000: 136). Las figuras son modalidades o maneras de pensamiento que no se quedan solo en el plano microestructural del texto, pues con las figuras damos a conocer expresivamente el mundo a partir de operaciones generales de nuestro pensamiento. Estas maneras de pensar, de ver el mundo ha llevado a Arduini a plantear el concepto de campo figurativo.

Los campos figurativos son espacios conceptuales que permiten el conocimiento del mundo a través del lenguaje. Arduini clasifica estos campos figurativos en seis tipos: metáfora, metonimia, sinécdoque, antítesis, repetición y elipsis.

El campo figurativo de la metáfora está integrado por la catacresis, el símbolo, el emblema, la alegoría, el símil, la personificación (o prosopopeya), la parábola y la propia metáfora. Sin duda, la metáfora ha sido una de las figuras más estudiadas y se ha dicho muchas veces que en ella opera un proceso de sustitución, se coloca una cosa en lugar de otra, pero ya varios críticos se han encargado de rechazar esa idea pues la metáfora se construye a partir de la asociación de dos ideas para crear una nueva idea, en ella se presenta una relación analógica.

El campo de la metonimia se presenta en el área de la contigüidad que lo distingue de la sinécdoque. En la metonimia tampoco existe la idea de sustitución, sino una relación de contigüidad que puede ser causa-efecto, efecto-causa, materiaobjeto, continente-contenido, concretoabstracto, abstracto-concreto, signo-cosa, lo físico-lo moral, instrumento-persona, autor-obra, entre otras más. 
El campo de la sinécdoque se desarrolla en el área de la inclusión y se clasifican en la parte por el todo, el todo por la parte, el género por la especie, la especie por el género, el singular por el plural y el plural por el singular.

El campo figurativo de la antítesis refleja un modo de pensar con oposiciones o contradicciones. Este campo presenta las siguientes figuras: la negación, la inversión, la ironía, el oxímoron, la paradoja, el hipérbaton.

El campo figurativo de la elipsis está integrado por figuras que operan con arreglo a un criterio de fragmentación de la expresión que puede llegar a su anulación o ausencia, pero la palabra o frase se esconde para mostrar, la ausencia sugiere la presencia de lo ausente. Las figuras de este campo son el silencio, la objeción, la reticencia, la perífrasis, el eufemismo y la elipsis propiamente dicha.

El campo figurativo de la repetición refleja un pensamiento obsesivo o reiterativo. Presenta las siguientes figuras: la repetición, la amplificación, la anadiplosis, el clímax, el quiasmo, la postposición, la anáfora, la epifora, el polisíndeton, la paronomasia, el poliptoto, la figura etimológica, la sinonimia, la equivocidad, el énfasis, la distinctio, la antanaclasis, la aliteración y la rima.

\section{La metáfora}

La metáfora es la figura retórica más utilizada no solo en la literatura, sino también en la vida cotidiana, pues nuestra manera de ver el mundo, de pensar y de hablar se construye a partir de metáforas. Lakoff y Johnson en su texto Metáforas de la vida cotidiana analizan y estudian esta figura y sostienen lo siguiente: .

Para la mayoría de la gente, la metáfora es un
recurso de la imaginación poética, y los adema-
nes retóricos, una cuestión de lenguaje extraor-
dinario más que ordinario. Es más, la metáfora
se contempla característicamente como un
rasgo sólo del lenguaje, cosa de palabras más
que de pensamiento o acción. Por esta razón,
la mayoria de la gente piensa que pueden arre-
glárselas perfectamente sin metáforas. Nosotros
hemos llegado a la conclusión de que la metáfo-
ra, por el contrario, impregna la vida cotidiana,
no solamente el lenguaje, sino también el pen-
samiento y la acción. Nuestro sistema concep-
tual ordinario, en términos del cual pensamos y
actuamos, es fundamentalmente de naturaleza
metafórica. (1995: 39)

La metáfora es más que una figura del lenguaje es un proceso constituyente del pensamiento humano; nuestro sistema conceptual ordinario es de naturaleza metafórica. Lakoff y Johnson clasifican las metáforas en tres tipos: estructurales, orientacionales y ontológicas. Las metáforas estructurales se presentan en los casos donde un concepto está estructurado metafóricamente a partir de otro (el tiempo es oro). Las metáforas orientacionales tienen como base la orientación espacial arriba-abajo, dentro-fuera, delante-detrás, profundo-superficial, centro-periferia o cerca-lejos; estas metáforas se originan a partir de la forma particular de nuestro cuerpo y su relación con el medio físico. Las metáforas ontológicas son aquellas en las que se consideran a los acontecimientos, actividades, emociones e ideas como entidades o sustancias (la mente es una máquina). 
William Hurtado de Mendoza realiza una revisión crítica sobre la metáfora e intenta dar una aproximación a la definición de metáfora quechua: "La metáfora quechua es un recurso de significación del que se vale la cultura. Esta cultura, la quechua, está viva, tiene presencia no solo en el Perú, sino en América del Sur, no obstante los siglos de dominación y los gobiernos de la vida republicana. La cultura quechua no es algo que se acabó en la Colonia. Persiste, permanece pese a la democracia y los nuevos doctrineros" (2009:109). Menciona que el proceso de creación de metáforas, entendido como un recurso de designación es propio de la cultura y abarca todos los campos y actividades donde se realice la lengua quechua en sus distintos dialectos y niveles. En conclusión, la metáfora es la expresión de una cultura y revela su cosmovisión, tanto así que todo el imaginario cultural se constituye en una hipermetáfora. La metáfora quechua sigue vigente y es un instrumento de referencia que se manifiesta en metáforas culturales, es decir, propias de la cosmovisión de la cultura andina. Esta metáfora quechua está determinada por las condiciones en las que se produce y tiene que ver con la situación de la cultura y la lengua.

\section{LA ETNOPOÉTICA, LA METÁFO- RA Y LA COSMOVISIÓN EN "TU- PAC AMARU KAMAQTAYTANCHIS- MAN (HAYLLI-TAKI) [A NUESTRO PADRE CREADOR TUPAC AMARU (HIMNO-CANCIÓN)]"}

La etnopoética es la poesía y que, a la vez, implica la concepción de poesía de una determinada cultura. Esto pone de relieve la condición del productor del texto poético, el cual es un sujeto indí- gena que a través de la poesía recrea un mundo simbólico construido por el lenguaje y a través del cual expone una cosmovisión, pero también expone el problema del contacto intercultural, pues el texto poético se produce dentro de una realidad social donde conviven varios sistemas lingüísticos, como es el caso de nuestro país, en una relación de desigualdad. La etnopoética se vincula con la poesía andina y la poesía quechua, que constituyen el refugio de la memoria y de la cosmovisión del mundo andino. A partir de este concepto de etnopoética, nosotros trataremos de identificar en el poema elegido las marcas o huellas textuales que reflejen la cosmovisión y el imaginario de la cultura andina.

Esta poesía etnocultural ha reflejado no solo la cosmovisión andina, sino también las relaciones asimétricas que se dan entre la cultura oficial y las culturas marginadas. La etnopoética utiliza la lengua materna del hablante, pero también la lengua oficial para establecer un diálogo intercultural entre el productor del texto y los lectores que no serán necesariamente de la misma cultura; por ello esta poesía es bilingüe de manera total o parcial. En el caso que nos compete, el poema de Arguedas está compuesto originalmente en lengua quechua, pero ha sido traducido por el mismo autor al español con la intención de establecer un diálogo o puente entre dos culturas, pues a pesar de que el poema está traducido al espańol se ven la huellas de la cultura andina, tales como la cosmovisión andina, la memoria cultural, las formas textuales propias de la cultura quechua, la relación del hombre y los dioses, y la representación de la naturaleza. 
Dicho lo anterior pasaremos a realizar un análisis del poema "Tupac Amaru kamaq taytanchisman (haylli-taki) [A nuestro padre creador Tupac Amaru (himno-canción)]".

\section{A. Estructura}

Debido a nuestro desconocimiento de la lengua quechua, haremos un análisis de la versión en castellano, que para suerte nuestra ha sido elaborada por el mismo José María Arguedas, pero como mencionamos anteriormente al traducir un texto de una lengua a otra este sufre modificaciones en los elementos formales que pueden afectar el contenido, pues la forma del texto se relaciona íntimamente con el contenido. En el caso de la poesía, la traducción puede afectarla más que a un texto narrativo, pues el poema posee rasgos formales como la rima, métrica y ritmo que constriñen el contenido. Pero en nuestro caso, nos ayuda el hecho de que el mismo autor del poema sea el traductor, pues en él se revela la intención de llegar con su poesía tanto a los quechua hablantes como a los hispanohablantes, ya que Arguedas es consciente de nuestra asimétrica realidad social y lingüística, y pretende que su poesía llegue a más lectores, pues sabemos que nuestro país es pluricultural y plurilingüe y que las relaciones entre culturas no son de igualdad.

Haciendo esta salvedad intentaremos un acercamiento del poema "Tupac Amaru kamaq taytanchisman (haylli-taki) [A nuestro padre creador Tupac Amaru (himno-canción)]". El poema que analizaremos está conformado por una dedicatoria del autor real a su madre india. Luego se intercalan 5 apartados en prosa y 4 en verso de distinta extensión e incluso el último apartado en prosa apenas presenta dos líneas. Esta conformación estructural encierra cierta dificultad pues la prosa, en este caso poética, no sigue los mismos lineamientos que el verso, a partir de ello se puede observar una intencionalidad del poeta que buscaremos develar.

El primer apartado en prosa empieza con la presentación del alocutario, nombrado por una voz poética en primera persona y en singular que invoca a Tupac Amaru hijo del dios Serpiente, el cual puede ver el futuro. El hablante lírico le informa sobre su presencia en un espacio y sobre su todavía existencia: "Aquí estoy, fortalecido por tu sangre, no muerto, gritando todavía" (1984: 11). Y se asume como integrante de una colectividad: "Estoy gritando, soy tu pueblo" (1984: 11). Luego este hablante menciona que ha sido recompuesto por el dios Serpiente al cual está hablándole en ese momento. Hace alusión al odio que siente por el invasor y si bien la enunciación se da desde el presente en un aquí y un ahora, también hace referencia a un pasado histórico en la que el alocutario Tupac Amaru luchó contra los españoles y su sangre fue derramada, que corresponderían al personaje histórico cuya forma es humana.

El primer apartado en verso presenta una digresión con respecto al apartado en prosa anterior, pues a partir de metáforas se configura una naturaleza viva que siente y sufre por la muerte de Tupac Amaru y que se demuestra a partir de la pregunta: “¿En dónde estás desde que te mataron por nosotros?" 
El segundo apartado en prosa contiene una invocación al dios Amaru o Serpiente para que escuche la naturaleza que se está levantando, insuflada por la memoria histórica o recuerdo de la muerte del dios cuando era hombre: “Nos estamos levantando, por tu causa, recordando tu nombre y tu muerte!" (1984: 13). Además en este apartado, el hablante lírico empieza a mencionar sobre la existencia y supervivencia de la colectividad, la memoria actualiza esta presencia en el mundo: “ $¡$ Estamos vivos; todavía somos!” (1984: 13).

El segundo apartado en verso habla del dolor colectivo de un pueblo, dolor compartido por la naturaleza que sufre por la situación de esta colectividad. Es importante señalar que este sufrimiento es actual, se manifiesta en el presente y este dolor es mayor que en el pasado: "Bajo la sombra de algún árbol, todavía llora el hombre, Serpiente Dios, más herido que en tu tiempo; perseguido, como filas de piojos" (1984: 13). Además señala, el hablante lírico, que el dolor es mayor en el hombre que en el niño, pues son perseguidos y viven en la pobreza. Con ella se hace alusión a la situación del hombre andino en el presente, la cual no ha mejorado, sino que ha empeorado.

En el tercer apartado en prosa, el hablante lírico habla del deseo de levantarse contra el invasor, además del vencimiento al temor hacia las armas del enemigo. $Y$ esta idea de levantarse para recuperar la libertad y la posesión de la tierra se realizará en nombre del dios Serpiente. Hace referencia al número de personas al compararlo con multitud de hormigas selváticas.
El tercer apartado en verso se contrapone al apartado anterior en prosa, pues el locutor del poema invoca al dios Serpiente a escuchar cómo las armas hieren y matan a este nosotros colectivo. Esta violencia se produce en todas partes, en las distintas regiones del país. Se presenta un fracaso del deseo de recuperación de la tierra frente a la violencia ejercida con medios materiales por la cultura dominante.

El cuarto apartado en prosa presenta al hablante lírico que nuevamente invoca al Dios Serpiente y le menciona que el presente ha empeorado, que los señores se han vuelto más terribles e incluso han corrompido a los propios hermanos del pueblo, a los cuales les han dado armas para que los maten. A pesar de ello hay una esperanza, pues a partir de la voz colectiva del nosotros informa al Dios Serpiente que han bajado a las ciudades. Luego a partir de la memoria histórica se recuerda el tiempo en que eran dueños de las tierras para luego ser despojados de ellas por los espańoles y debido a la actual situación de pobreza se han dispersado en miles de pueblos ajenos. Hay algunos que se han aferrado a sus tierras y se han quedado, pero mantienen viva la ira contra los señores. La vida terrible que llevan les ha hecho perder el miedo a la muerte, pues el sufrimiento los ha fortalecido. Esta fuerza que da la muerte puede llevarlos a revolver el mundo. Luego el hablante lírico se instala en una voz individual para informarnos que está en Lima, en el pueblo de los falsos wiraqochas, donde se ha instalado en Pampa de Comas, lugar en el cual ha construido una casa con mucho sacrificio, acompańado del canto. A este nuevo hogar ha trasladado el imaginario de su 
pueblo. Tras esto el hablante lírico toma la voz colectiva para decirle al Dios Serpiente que están removiendo, envolviendo, en resumen transformando la ciudad con la cultura andina, y otra vez menciona la música como arte que une. Hay también una idea de purificación, de lavar la culpa, la memoria de la historia que está guardada en la mente de los falsos wiraqochas. La unión de los miembros de la colectividad marginada busca transformar la ciudad occidental que los desprecia en un pueblo de hombres donde haya trabajo, felicidad, limpieza, sin odio y sin maldad. Es decir, que lo que busca el yo poético es la transformación de esta ciudad occidentalizada en un pueblo donde los valores de la cultura andina se impongan, donde haya comunión entre los hombres y de estos con su mundo natural. La invasión ya no es de los señores blancos al mundo andino, sino de este mundo, al cual pertenece el hablante lírico, al mundo de los blancos.

En el cuarto apartado en verso, el yo poético se dirige al alocutario para pedirle que espere con tranquilidad mientras canta, baila, se alza, aprende la lengua castellana y entiende los instrumentos tecnológicos de los falsos wiraqochas. Es decir, que se produce una apropiación de los elementos culturales del otro, tanto que este otro occidental, hijos de wiraqochas, puedan hablar y escuchar al Dios Serpiente y establecer el diálogo entre una cultura y otra. También hace alusión a la transformación de los hombres víctimas de la violencia en águilas y cóndores libres. El hablante lírico propone conseguir lo que no pudo Tupac Amaru. Luego menciona otra vez la tranquilidad para esperar y después enumera elementos y seres de la naturale- za que serán regocijados cuando se consiga un nuevo mundo donde la muerte venga sola sin ser producida por la violencia de las armas. Solo allí se procederá a la unión e identificación entre el hombre y su mundo.

El quinto apartado en prosa contiene apenas dos líneas, en las cuales el hablante lírico invoca al Dios Serpiente para que descienda y le infunda aliento y fuerza.

\section{B. Figuras literarias}

Tras leer el poema "Tupac Amaru kamaq taytanchisman (haylli-taki) (A nuestro padre creador Tupac Amaru (himno-canción)]" podemos encontrar el predominio del campo figurativo de la metáfora, pues se ve el uso recurrente de la metáfora, el símil y la personificación. El uso del campo figurativo de la metáfora revela en el autor un pensamiento analógico o metafórico pues se asocian dos ideas para crear una nueva. Como ejemplos de metáfora, tenemos:

\footnotetext{
Está cantando el río, está llorando la calandria está dando vueltas el viento; día y noche la paja de la estepa vibra; nuestro río sagrado está bramando; en las crestas de nuestros Wamanis montañas en sus dientes, la nieve gotea y brilla.

¿En dónde estás desde que te mataron por nosotros? (1984: 11)
}

Los versos anteriores presentan metáforas verbales que a la vez se relacionan con la prosopopeya, pues se le atribuyen rasgos humanos a seres como el río, la calandria, el viento, la paja y a las montañas. Esto muestra la idea de que los elementos naturales están vivos, lo cual refleja una concepción panteísta de la na- 
turaleza, propia de la cosmovisión andina. Otra metáfora de tipo A es B, es la siguiente: (yo) soy tu pueblo que implica la idea de que una persona es todas las personas. El yo poético se asume como una colectividad o parte de una colectividad; esta concepción colectivista del ser es propia de la cultura andina y esto se puede ligar con la idea de runa, concepto estudiado por Landeo, y que es mencionado por Gonzalo Espino en su artículo "La poesía quechua de José María Arguedas: la categoría runa" (2011): "Runa, entonces, demanda una conceptualización que permita situarlo en su relación con una colectividad -real o imaginaria, para los tiempos actuales- feliz, porque evoca una pertenencia situada, localizada. Un runa no se nombra a sí mismo, necesita presentarse como parte de, se define por un conjunto de particularidades étnicas o culturales".

Igualmente, dentro de este tipo de metáfora $A$ es $B$, se da otro ejemplo casi al final del poema y que resume de alguna manera la cosmovisión del poeta y de su cultura: "El mundo será el hombre, el hombre el mundo" (1984: 19). Esta metáfora reitera la cosmovisión panteísta de la naturaleza, rasgo característico de la religión andina. El panteísmo es la creencia de que el mundo y Dios son lo mismo. Cada criatura es un aspecto o una manifestación de Dios, que es concebido como el actor divino que desempeña a la vez los innumerables papeles de humanos, animales, plantas, estrellas y fuerzas de la naturaleza.

Otra figura recurrente dentro del campo figurativo de la metáfora es el símil, el cual es una comparación directa entre dos entes. Podemos hallar por ejemplo:
Tus ojos de serpiente dios que brillaban como el cristalino de todas las águilas

Tu rostro era como el gran cielo

Hemos bajado como las interminables filas de hormigas de la gran selva (1984:14)

Estos símiles también reflejan un pensamiento relacional o analógico propio del campo de la metáfora, pues se relacionan dos ideas para crear una nueva, pero lo que notamos es que se liga en las comparaciones elementos de la naturaleza que revelan la cosmovisión andina de la naturaleza como un todo que refleja la existencia de la divinidad, y también se refleja nuevamente la idea de la colectividad.

\section{Interlocutores}

Los interlocutores del poema están representados de manera plena y directa. A través de la lectura podemos distinguir que el poema se construye a modo de oración o plegaria, desde un yo poético que pasa de manera natural de una voz individual a una voz colectiva y que se dirige a un tú representado por el dios Tupac Amaru. Por lo tanto, desde el inicio el alocutario aparece de manera manifiesta con el nombre de Tupac Amaru, hijo del Dios Serpiente. Este alocutario se configura como un ser a la vez histórico y mítico, pues Tupac Amaru es el nombre de dos descendientes del linaje inca que se rebelaron contra el poder del invasor español; este rasgo de rebelde se configura a lo largo del poema. Pero esta imagen humana está unida a la imagen divina y mítica del dios Amaru o Serpiente, el cual es una divinidad relacionada con el agua. Con respecto al elemento de la comunicación que corresponde al emisor, encon- 
tramos un locutor-personaje o hablante lírico representado en primera persona que asume una voz individual (yo) y a la vez colectiva (nosotros). Dichas marcas de persona se hallan en los verbos que se utilizan en el poema.

(yo) Estoy gritando, soy tu pueblo (nosotros) ¿Estamos vivos; todavía somos!

Este hablante lírico que transita del singular al plural se asume como parte integrante de una colectividad; es consciente de su sentido de pertenencia a un grupo y establece un acto de petición más que de alabanza. Por ello, aunque el poema es nombrado en español como himno (correspondiente al haylli) tiene un tono elegiaco.

\section{Cosmovisión}

A lo largo del poema podemos notar rasgos textuales que revelan la cosmovisión a partir de la cual está construido el poema. La cosmovisión que se revela es andina y perteneciente a la cultura quechua. La invocación del yo lírico o poético se realiza al dios Tupac Amaru o dios Serpiente. Este alocutario, como mencionamos presenta dos naturalezas: una histórica, los dos Tupac Amaru que lucharon contra el español, pero fueron derrotados; y otra mítica, el dios Serpiente, deidad vinculada al agua. Esta tensión y unión entre lo histórico y lo mítico está presente a lo largo del poema, pues $\mathrm{Tu}$ pac Amaru ha muerto como ser humano, pero ha regresado de la muerte como un dios y pronto ha de volver para restablecer el orden anterior, bajo las ideas de comunión, trabajo e integración con la naturaleza; el ciclo de la vida y la muerte se engarzan debido a esta concepción cíclica del tiempo. Por lo tanto, en el poema se configura un tiempo cíclico propio del mito y que reflejan claramente la cosmovisión andina. La idea del retorno está ligada al tiempo cíclico. En el poema podemos observar que el antiguo orden va a retornar pues ya el pueblo del cual forma parte el hablante lírico ha salido de sus lugares de orígenes y ha llegado a la ciudad de Lima, centro del poder de los señores o falsos wiraqochas. No solo han cercado la ciudad de manera física, sino también de manera cultural pues se han ido apropiando de la lengua y tecnologías del invasor hispano: "Aprendo ya la lengua de Castilla, / entiendo la rueda y la máquina" (1984: 17). Pero sin olvidar su propia cultura pues a pesar de que han dejado sus pueblos han llevado sus costumbres y tradiciones: "El río de mi pueblo, su sombra, su gran cruz de madera, las yerbas y arbustos que florecen, rodeándolo, están, están palpitando dentro de esa casa; un picaflor dorado juega en el aire, sobre el techo" (1984: 16-17). En esto se revela también el tiempo histórico, pues el autor a lo largo del texto ha apelado a la historia para construir el poema, pues hace alusión a la invasión española, la postergación y explotación actual del indio en la República y el proceso de migración que se ha operado en la sociedad peruana, sobre todo en Lima, donde todas las sangres conviven y donde la cultura de ese otro marginado se ha ido instalando $y$ mezclándose con elementos de la cultura de la cultura hegemónica occidental; la invasión ahora se produce al revés pues elementos culturales de la cultura andina perviven en formas occidentales, pero 
el deseo del hablante lírico es que la cosmovisión andina sea la que predomine y no la cosmovisión occidental. La idea de comunión y de integración del hombre con el mundo eliminará la violencia y la muerte vendrá sola: "La santa muerte vendrá sola, ya no lanzada con hondas trenzadas ni estallada por el rayo de pólvora. / El mundo será el hombre, el hombre el mundo, todo a tu medida" (1984: 19). Esta cosmovisión andina también se manifiesta en la concepción de la naturaleza, pues en el imaginario quechua, el hombre y la naturaleza viven en comunión y el hombre vive en comunicación con el cosmos, por ello, cuando el poblador andino sufre también la naturaleza sufre: "Escucha el frío de mi sangre, su temblor helado. I Escucha sobre el árbol de lambras el canto de la paloma abandonada, nunca amada; / el llanto dulce de los caudalosos ríos, de los manantiales que suavemente brotan al mundo" (1984: 13). Por ello, la naturaleza en el poema tiene una función integradora con los humanos. Esta integración también se produce entre los individuos que se asumen como uno solo con un sentido de pertenencia a una comunidad donde prima la solidaridad y se da valor al trabajo: "Hemos de convertirla en pueblo de hombres que entonen los himnos de las cuatro regiones de nuestro mundo, en ciudad feliz, donde cada hombre trabaje, en inmenso pueblo que no odie y sea limpio, como la nieve de los dioses montańas donde la pestilencia del mal no llega jamás" (1984: 17). Y podemos encontrar también dentro de esta cosmovisión el papel que tiene la música como parte de la armonía cósmica, pues en la cultura andina la música acompaña sus actividades agrarias.
En resumen, el poema revela, a partir de las figuras como la metáfora, la cosmovisión andina del tiempo cíclico, la integración, la comunicación del hombre con la naturaleza o el cosmos y la identificación del hombre como parte de una colectividad, el papel de la música como parte de la armonía cósmica. Tal como sostiene Arduini, las figuras configuran o construyen una realidad y reflejan una manera de pensar o cosmovisión del mundo que tiene que ver con la cultura; y tomando las ideas de Hurtado de Mendoza, la metáfora, como recurso de cognición, permite la aproximación al pensamiento de la cultura quechua, que debe asumirse como dinámico, pues presenta componentes prehispánicos $\mathrm{e}$ hispanos. Como vemos en el poema, la metáfora refleja la concepción panteísta del hombre andino, la relación armoniosa del hombre con la naturaleza, la idea de un tiempo cíclico y el carácter colectivista de la cultura quechua. Esto revela la persistencia de la metáfora quechua que se manifiesta como metáforas culturales a pesar de la interferencia del sistema lingüístico y cultural occidental.

\section{CONCLUSIONES}

1. La poesía de José María Arguedas, a partir del poema analizado, revela las tensiones y uniones entre la tradición cultural quechua y la forma escritural española.

2. El poema analizado presenta como eje articulador el campo figurativo de la metáfora, donde esta figura junto al símil son las más recurrentes. Este campo figurativo revela un pensamiento analógico predominante en la cultura quechua. 
3. Las metáforas usadas por el poeta revelan una cosmovisión andina donde se percibe la concepción panteísta, el tiempo cíclico, la integración y comunicación del hombre con la naturaleza y la concepción del habitante andino como parte de una colectividad.

4. El poema se construye tanto a partir de un discurso mítico como del discurso histórico que trata de unir el presente, el pasado y el futuro.

\section{BIBLIOGRAFIA}

ARGUEDAS, José María. Katatay. Lima: Editorial Horizonte, 1984.

ARDUINI, Stefano. Prolegómenos a una teoria general de las figuras. Murcia: Universidad de Murcia, Servicio de Publicaciones, 2000.
ESPINO RELUCÉ, Gonzalo. "La poesía quechua de José María Arguedas: la categoría Runa" en Arguedas Centenario. Actas del Congreso Internacional José María Arguedas. Vida y Obra (1911-2011). Comp. Marco Martos, Javier Morales y Gladys Heredia. Lima: Academia de la Lengua Peruana / Facultad de Letras y Ciencias Humanas UNMSM / Ed. SM, 2011: 35-44.

LAKOFF, George y Mark JOHNSON. Metáforas de la vida cotidiana. Madrid: Ediciones Cátedra S. A., 1995.

HUAMÁN, Miguel Ángel. "La poesía de José María Arguedas y la utopía andina". En Alma Máter 17. Lima: UNMSM, 1999.

HURTADO DE MENDOZA, William. Metáfora y pensamiento de la cultura quechua. Lima: Asamblea nacional de Rectores, 2009 . 